\title{
Linkage analysis of a large pedigree with hereditary sideroblastic anaemia
}

\author{
J S Noble, G R Taylor, M S Losowsky, R Hall, G Turner, R F Mueller, A D Stewart
}

\begin{abstract}
A large pedigree showing a history of pyridoxine responsive $X$ linked sideroblastic anaemia was screened with several polymorphic DNA markers from the $X$ chromosome. Linkage analysis between each marker and disease status was performed, giving a maximum two point lod score of 3.64 at zero recombination with the microsatellite marker PGK1P1 at Xq11.2-12. Close linkage to PGK at Xq13.3, one of the candidate regions for $X$ linked sideroblastic anaemia, was excluded. Linkage to DNA markers distal to PGK and at Xp21 was also excluded. Multipoint linkage analysis was performed with markers located between Xq11.2-21. The maximum map specific lod score obtained was 3.56 at PGK1P1 (Xq11.2-12). Linkage remained significant over the interval $20 \mathrm{cM}$ proximal to PGK1P1 and $5 \mathrm{cM}$ distal to PGK1P1, with definite exclusion around the PGK locus. The most likely location of the gene involved in sideroblastic anaemia in this pedigree is therefore within the pericentromeric region of the $X$ chromosome. This region includes the erythroid 5-aminolaevulinate synthetase gene of the haem synthesis pathway, which is a candidate gene for $X$ linked sideroblastic anaemia located at Xp11.21.
\end{abstract}

(f Med Genet 1995;32:389-392)

The sideroblastic anaemias are either inherited or acquired. The inherited form generally follows an $\mathrm{X}$ linked recessive pattern although some cases of autosomal inheritance have been documented. ${ }^{1} \mathrm{X}$ linked hereditary sideroblastic anaemia is a rare disorder, manifesting mainly in males, usually in childhood or adolescence. Carrier females may be affected but usually show mild or no anaemia. The mode of inheritance in the pedigree investigated in this study is $\mathrm{X}$ linked recessive.

The person affected with $\mathrm{X}$ linked hereditary sideroblastic anaemia often presents with a dimorphic, hypochromic, microcytic anaemia. The serum iron is usually raised, the total iron binding capacity is saturated, and the serum ferritin may also be slightly raised. In the bone marrow 10 to $40 \%$ of erythroblasts contain stainable iron granules arranged in a ring around the nucleus, the erythroblast mitochondrion being loaded with iron. Ringed sideroblasts are the diagnostic feature of the sideroblastic anaemias. Hereditary sideroblastic anaemia is not generally life threatening; death from the condition is rare but can result from haemochromatosis owing to excess iron deposition in the tissues and organs. ${ }^{3}$

Microcytic hypochromic anaemia is generally associated with iron deficiency, but in hereditary sideroblastic anaemia iron deficiency is clearly not the cause; the patient is iron overloaded. The defect appears to be in iron utilisation, most probably in the synthesis of haem. Haem is synthesised in the mitochondria, so that a failure to utilise iron could cause the observed accumulation of iron in the mitochondria. The first enzyme of the erythroid haem synthesis pathway, 5-aminolaevulinate synthetase, is located on the $\mathrm{X}$ chromosome and is therefore a candidate gene for $\mathrm{X}$ linked sideroblastic anaemia. Astrin and Bishop ${ }^{4}$ isolated an aminolaevulinic acid synthetase, ALAS-2, that is only expressed in erythroid cells and assigned the gene involved to the $\mathrm{X}$ chromosome. The gene has since been mapped to $\mathrm{Xp} 11.21^{56}$ and characteristics of the gene and protein have been described.

A number of patients with $\mathrm{X}$ linked sideroblastic anaemia, including affected members of the pedigree investigated in this study, have shown some response to treatment with pyridoxine, vitamin B6. Pyridoxal phosphate is derived from pyridoxine and is a co-enzyme for ALAS-2. Cotter $e t a l^{8}$ have described a sequence variant in exon 9 of the ALAS-2 gene in a single male with pyridoxine responsive $\mathrm{X}$ linked sideroblastic anaemia. Exon 9 is thought to code for part of the pyridoxal phosphate binding site. $\mathrm{A}$ single $\mathrm{T}$ to $\mathrm{A}$ base change in codon 471 resulting in an isoleucine to asparagine substitution was observed. ${ }^{8}$ Cox et $a l^{9}$ have since described a sequence variant in exon 8 of ALAS-2 in two affected males and one female carrier of a pedigree with pyridoxine responsive X linked sideroblastic anaemia. Exon 8 is also believed to code for part of the pyridoxal phosphate binding site. A single $C$ to $G$ base change in codon 388 was observed resulting in a threonine to serine substitution. ${ }^{9}$

However, hereditary sideroblastic anaemia appears to be genetically heterogeneous as linkage to other regions of the $\mathrm{X}$ chromosome has also been reported. Pagon et al ${ }^{10}$ described a pedigree in which hereditary sideroblastic anaemia and the non-progressive spinocerebellar syndrome, ataxia, were co-segregating in an $\mathrm{X}$ linked recessive fashion. Linkage to phosphoglycerate kinase at Xq13 (maximum lod score of 2.6 at a recombination fraction of zero) has since been reported in the pedigree. ${ }^{11}$ The microsatellite in intron 7 of ALAS-2 was uniformative for linkage in the pedigree, ${ }^{12}$ but linkage to DXS14, which maps 


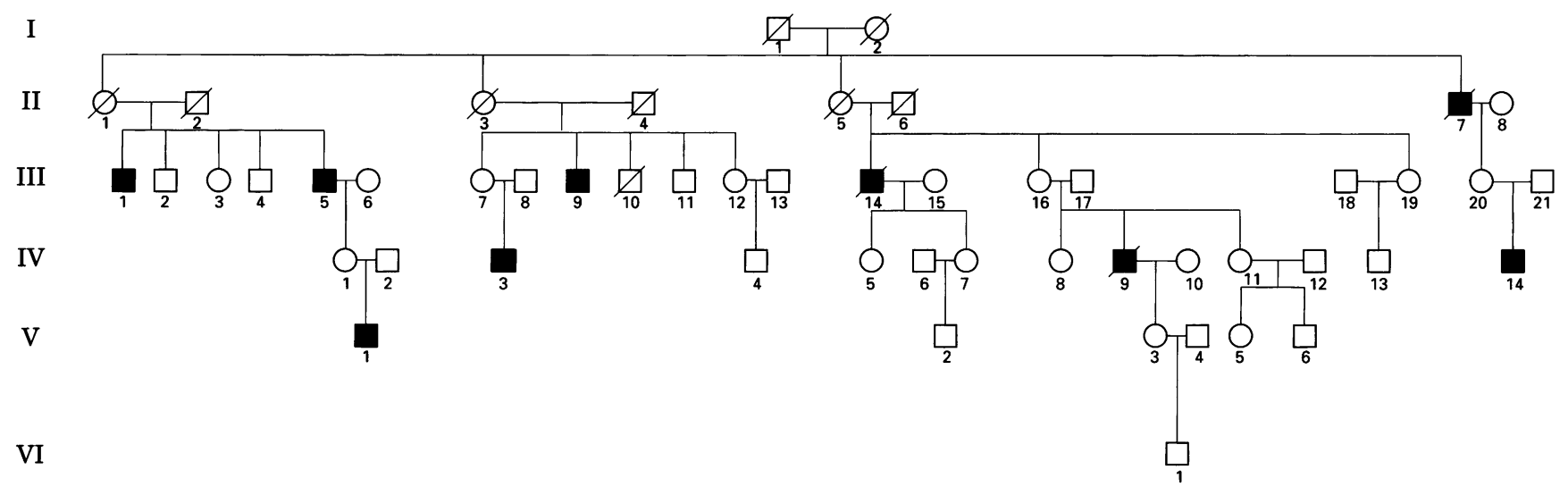

Figure 1 Pedigree of the family with $X$ linked sideroblastic anaemia.

close to ALAS-2, was excluded. ${ }^{11} \mathrm{X}$ chromosome abnormalities (including rearrangements involving Xq13) have been observed in some patients with idiopathic acquired sideroblastic anaemia. ${ }^{13}$ However, the basic biochemical defect involved in idiopathic acquired sideroblastic anaemia may be different from that in hereditary sideroblastic anaemia. Candidate regions for the gene responsible for hereditary sideroblastic anaemia in the pedigree investigated with linkage markers in this study were Xq13 and Xp11.21; other regions of the $\mathrm{X}$ chromosome were also investigated.

\section{Materials and methods \\ PATIENTS \\ The part of the pedigree investigated is shown in fig 1 ; the proband is member III. 1 . A more complete pedigree may be seen in Losowsky and Hall. ${ }^{2}$ Affected males were diagnosed on the basis of peripheral blood film appearance, the occurrence of ringed sideroblasts in the bone marrow, and serum iron levels. The pedi- gree members genotyped included six affected males, seven unaffected males, and six obligate carrier females.}

MICROSATELLITE AND RFLP ANALYSIS

Whole blood was collected into EDTA and

DNA extracted by standard methods. Details of the DNA markers used are listed in table 1.

Table 1 DNA markers. All microsatellites are denoted by (CA)n. The chromosomal location and relevant gene (where applicable) are shown. All primer sequences can be found in the references

\begin{tabular}{llll}
\hline Marker & $\begin{array}{l}\text { No of alleles } \\
\text { in the pedigree }\end{array}$ & Location/gene ${ }^{14}$ & Reference \\
\hline Dys3' (CA)n & 2 & Xp21.1 dystrophin & 15 \\
pERT87-15/XmnI & 2 & Xp21 dystrophin & 16 \\
Dys 5'II (CA)n & 3 & Xp21.3 dystrophin & 17 \\
Dys 5'I (CA)n & 4 & Xp21.3 dystrophin & 17 \\
MAOB (CA)n & 3 & Xp11.4-11.3 monoamine oxidase B & 18 \\
DXS426 (CA)n & 2 & Xp11.23-11.3 & 19 \\
ALAS-2 (CA)n & 3 & Synthetase & 12 \\
PGK1P1 (CA)n & 2 & Xq11.2-12 & 20 \\
DXS453 (CA)n & 4 & Xq11.2-12 & 21,22 \\
PGK-PY2 (CA)n & & Xq13.3 phosphoglycerate kinase 1 & 23 \\
PGK-PY5 (CA)n & 3 & Xq21-22 & 23 \\
DXS456 (CA)n & 4 & Xq24-26 & 19 \\
DXS424 (CA)n & 4 & Xq27 factor IX & 24 \\
FIX/HhaI & 2 & & 25 \\
FVIII/BcII & 2 & & \\
\hline
\end{tabular}

PCR was carried out in a total reaction volume of $25 \mu \mathrm{l}$ with 50 to $100 \mathrm{pmol}$ of each primer, approximately $250 \mathrm{ng}$ of DNA, Taq DNA polymerase reaction buffer $(10 \mathrm{mmol} / 1$ tris-Cl $\mathrm{pH} 8.0,45 \mathrm{mmol} / 1 \mathrm{KCl}, 1.5 \mathrm{mmol} / 1 \mathrm{MgCl}_{2}$, $0.01 \%$ triton-X 100$)$ and $200 \mu \mathrm{mol} / 1$ of each dNTP (RFLPs) or $250 \mu \mathrm{mol} / 1 \mathrm{dCTP}$, dGTP, and dTTP, $2.5 \mu \mathrm{mol} / 1 \mathrm{dATP}, 80 \mu \mathrm{mol} / 1$ (approximately $2.5 \mu \mathrm{Ci}$, Amersham) of $\alpha{ }^{35} \mathrm{~S}$ dATP or $\alpha-{ }^{33} \mathrm{P}$ dATP (microsatellites) and $1.25 \mathrm{U}$ of Taq DNA polymerase (Promega). PCR was carried out for 30 cycles (RFLPs) and 24 to 30 cycles (microsatellites). Primers were annealed at 50 to $60^{\circ} \mathrm{C}$ and extended at $72^{\circ} \mathrm{C}$ for RFLPs and annealed and extended at 55 to $60^{\circ} \mathrm{C}$ for microsatellites as described in Noble $e t$ $a l .{ }^{26}$ For RFLPs, the PCR product was digested with the appropriate restriction endonuclease and resolved through a $2 \%$ agarose gel. For microsatellites an equal volume of loading buffer $(95 \% \mathrm{v} / \mathrm{v}$ deionised formamide, $0 \cdot 1 \% \mathrm{w} / \mathrm{v}$ xylene cyanol, $0 \cdot 1 \% \mathrm{w} / \mathrm{v}$ bromophenol blue, $100 \mathrm{mmol} / 1$ tris-borate (pH 8.3), $2 \mathrm{mmol} / 1$ EDTA) was added to the PCR product before denaturation and electrophoresis through an $8 \%$ denaturing polyacrylamide gel. The alleles were scored with allele 1 representing the largest allele within the pedigree and allele 2 representing the second largest allele, etc.

\section{GENETIC LINKAGE ANALYSIS}

Two point linkage analysis was performed with MLINK (LINKAGE version 5.03) with a model of recessive $\mathrm{X}$ linked inheritance. All marker alleles were assigned equal frequencies according to the number of alleles seen in the family for each marker (table 1). Recalculation with equal frequencies for larger numbers of alleles yielded slightly higher positive lod scores in this family. These were not used, as it is most likely that the allele associated with the disease will be a more common one and a more conservative approach was preferred. To facilitate linkage analysis the genotypes of the markers located at PGK (PY2 and PY5) were combined to produce haplotypes relating to a single marker, PGK combined. This is possible because, as expected, no recombination was observed between these two markers. Five alleles were assigned to this marker. The allele frequency of $\mathrm{X}$ linked hereditary sideroblastic 


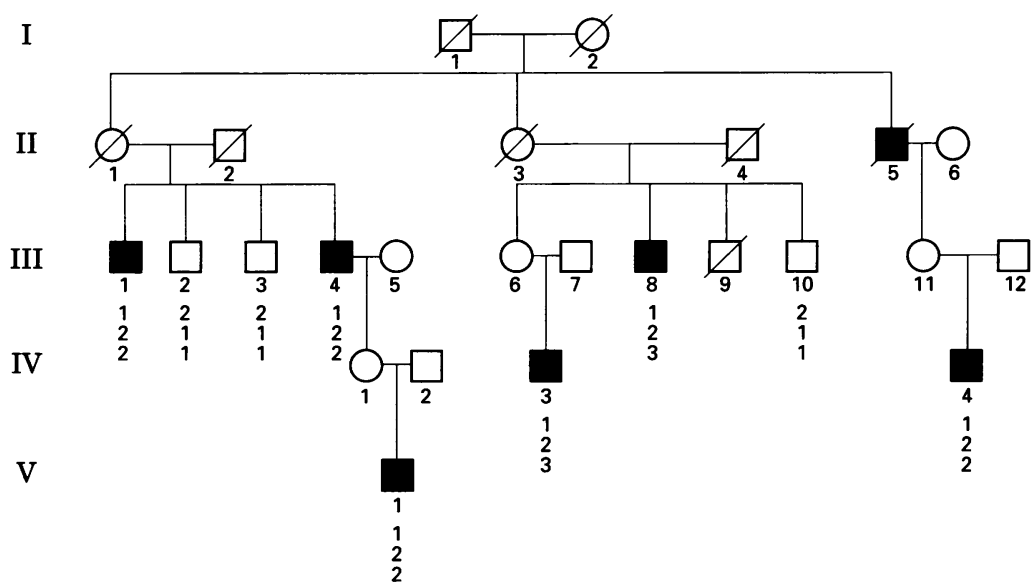

Figure 2 Key pedigree members with the haplotypes for the markers PGK1P1, DXS453, and PGK combined (PGK-PY2 and PGK-PY5) shown below each member.

anaemia was taken to be $1 / 10000$ with a mutation rate of $1 \times 10^{-6}$. Complete penetrance was assumed for males; the penetrance in heterozygotes was given as zero, as no attempt was made to ascertain carrier status from clinical data.

For multipoint linkage analysis, the same parameter values were used and lod scores were calculated with the sideroblastic anaemia locus moved between the loci PGK1P1, DXS453,

Table 2 Two point analysis of hereditary sideroblastic anaemia versus marker

\begin{tabular}{llrrrrr}
\hline Marker & $0.000 \theta$ & $0.001 \theta$ & $0.05 \theta$ & $0 \cdot 10 \theta$ & $0.20 \theta$ & $0.30 \theta$ \\
\hline Dys 3' and DXS426 & 0.13 & 0.13 & 0.10 & 0.07 & 0.02 & -0.01 \\
pERT87-15/XmnI & $-\infty$ & -3.87 & -0.60 & -0.14 & 0.15 & 0.16 \\
Dys 5'II & 0.70 & 0.70 & 0.63 & 0.55 & 0.41 & 0.27 \\
Dys 5'I & $-\infty$ & -1.60 & -0.00 & 0.19 & 0.25 & 0.19 \\
DXS456 & $-\infty$ & -1.25 & 0.35 & 0.54 & 0.59 & 0.48 \\
DXS424 & $-\infty$ & -5.36 & -0.47 & 0.21 & 0.64 & 0.64 \\
FIX/Hhal & $-\infty$ & -6.74 & -1.72 & -0.91 & -0.24 & 0.01 \\
FVIIIBcII & $-\infty$ & -2.59 & -0.91 & -0.63 & -0.36 & -0.21 \\
MAOB & 0.89 & 0.88 & 0.78 & 0.68 & 0.49 & 0.31 \\
ALAS-2 & 0.76 & 0.76 & 0.67 & 0.58 & 0.41 & 0.25 \\
PGK1P1 & 3.64 & 3.63 & 3.33 & 3.01 & 2.34 & 1.63 \\
DXS453 & 3.51 & 3.50 & 3.16 & 2.81 & 2.07 & 1.28 \\
PGK combined & $-\infty$ & -0.94 & 2.10 & 2.32 & 2.12 & 1.6 \\
\hline
\end{tabular}

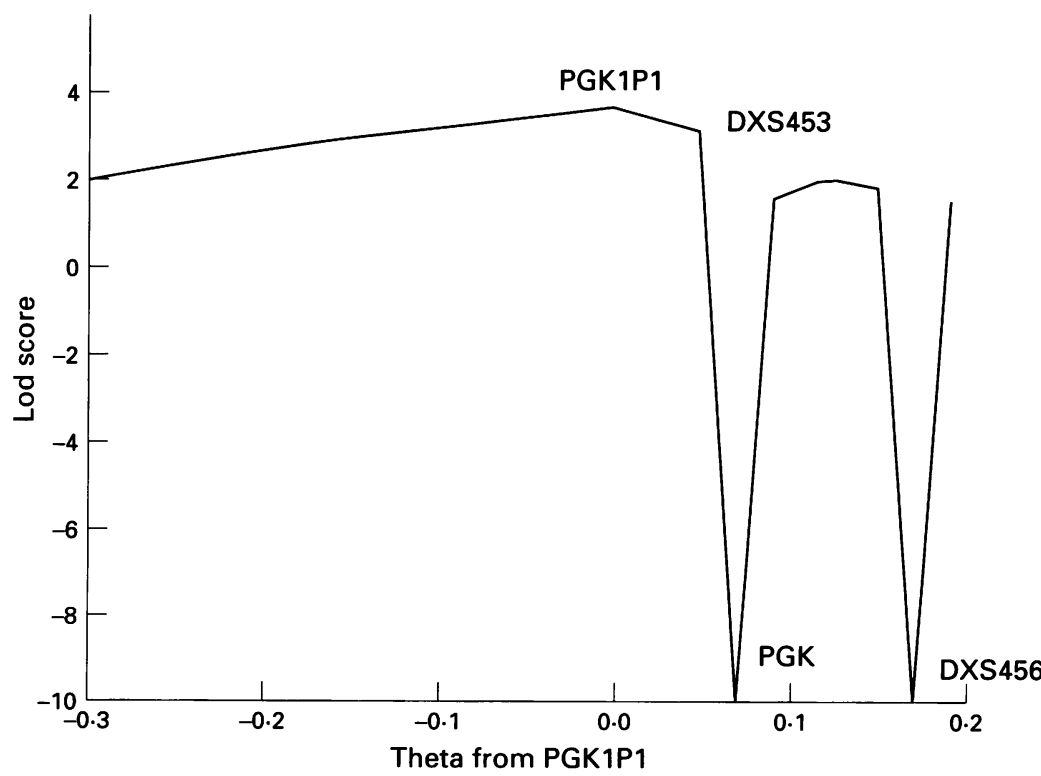

Figure 3 Plot of multipoint analysis. Lod score is plotted against $\theta$ from PGK1P1. Distances from PGK1P1 are $0 \cdot 05 \theta$ for DXS453, 0.07 0 for PGK, and $0 \cdot 17 \theta$ for DXS456.
PGK combined, and DXS456 using LINKMAP (version 5.10). The recombination fractions between PGK1P1-DXS453, DXS453PGK, and PGK-DXS456 were estimated from published data. The distance between PGK1P1 and PGK was estimated to be $7 \mathrm{cM}$, and PGK1P1 is thought to be proximal to DXS453, although this is not finally confirmed. ${ }^{1422}$ For the purpose of multipoint linkage analysis, PGK1P1 and DXS453 were placed $5 \mathrm{cM}$ apart and PGK was placed $2 \mathrm{cM}$ from DXS453. However, moving DXS453 within the $7 \mathrm{cM}$ interval assumed between PGK1P1 and PGK did not significantly affect the results. DXS456 was placed $10 \mathrm{cM}$ from PGK.

\section{Results}

Genotypes were obtained from the descendants of II $\cdot 1$ and II. 3 only for the markers Dys3', pERT87-15/XmnI, Dys 5'II, Dys 5'I, DXS426, DXS456, DXS424, FIX/HhaI, and FVIII/Bc/I. Genotypes of the remaining markers were obtained for the whole pedigree. The haplotypes, of key members only, for PGK1P1, DXS453, and PGK combined are shown in fig 2.

The results of two point linkage analysis between $\mathrm{X}$ linked sideroblastic anaemia and each marker over a range of values for $\theta$ from 0 to 0.3 are shown in table 2 . The results of multipoint linkage analysis are shown in fig 3.

\section{Discussion}

Pedigree member I 2 was an obligate carrier of HSA as she had an affected son. It is possible to infer unambiguously the haplotypes in $I \cdot 1$ and I.2 for PGK combined (fig 2). The two obligate carrier daughters, II $\cdot 1$ and II $\cdot 3$, have inherited different maternal alleles at the PGK combined locus. The alleles were also different for the DXS456 and DXS424 loci (not shown). There has clearly been a recombination event between the disease locus and these loci in at least one of the daughters. For the PGK1P1 and DXS453 loci, only one of the haplotypes in $\mathrm{I} \cdot 2$ can be inferred, because it is inherited by all the branches of the family with affected members that have been analysed. It is also present in all the affected males, and absent from the unaffected males. This suggests that this chromosomal region could be implicated in the aetiology of the disease.

Two point linkage analysis of hereditary sideroblastic anaemia versus marker was performed (table 2). The microsatellites at PGK1P1, DXS453, and markers at PGK provided information around $\mathrm{Xq} 13$. The maximum two point lod scores were 3.64 at zero recombination with microsatellite PGK1P1 (located at Xq11.2-12) and 3.51 at zero recombination with microsatellite DXS453, assigned to the same region. The slight difference in the lod scores is because of differences in assumed allele frequencies as both markers were fully informative. Linkage was excluded with the markers located at PGK (Xq13.3) at $0 \%$ recombination. Linkage to markers distal to Xq13 (DXS456, DXS424, FIX/HhaI, and 
FVIII/BclI) and to the dystrophin (Xp21) markers pERT87-15/XmnI and the Dys 5'I microsatellite was also excluded. The microsatellites Dys 3', Dys 5'II, DXS426, MAOB, and ALAS2 produced no significant information; in particular, all affected members and obligate carriers possessed an allele of the ALAS-2 microsatellite in common, but the marker had a low degree of heterozygosity in the family. Map specific multipoint linkage analysis between hereditary sideroblastic anaemia, PGK1P1, DXS453, PGK combined, and DXS456 was also performed (fig 3). The maximum lod score obtained from multipoint analysis was 3.56 at PGK1P1. This value is strongly supportive of linkage in the PGK1P1 region. The 10 -fold support interval (lod $>2 \cdot 6$ ) extends $20 \mathrm{cM}$ proximal to PGK1P1, and $5 \mathrm{cM}$ distal to PGK1P1 with definite exclusion of the PGK locus. The lod scores suggest that the disease locus in this family is 40 times more likely to be located proximal rather than distal to PGK.

These results very strongly suggest that the candidate region for hereditary sideroblastic anaemia in this pedigree is the pericentromeric region of the $\mathrm{X}$ chromosome. This region includes the ALAS-2 gene localised to Xp11.21. The reports of linkage to PGK at $\mathrm{Xq} 13^{11}$ and of sequence variants in ALAS-2 at Xp11.21 ${ }^{89}$ indicate HSA is likely to be a genetically heterogeneous disorder. Linkage to PGK (Xq13) has been excluded in the pedigree investigated in this study, so that ALAS-2 is a strong candidate gene for the $\mathrm{X}$ linked sideroblastic anaemia found in this pedigree.

The authors would like to acknowledge the Imperial Cancer Research Fund Genetic Epidemiology Laboratory (University of Leeds), especially Dr A Williams, for assistance in collecting the family and the analysis. The authors would also like to thank Dr A P Monaco of the Imperial Cancer Research Fund thaboratories, Oxford for providing unpublished sequences from the PGK-PY2 and PY5 microsatellites.

1 van Waveren Hogervorst GD, van Roermund HPC, Snijders PJ. Hereditary sideroblastic anaemia and autosomal inheritance of erythrocyte dimorphism in a Dutch family. Eur $\mathcal{f}$ Haematol 1987;38:405-9.

2 Losowsky MS, Hall R. Hereditary sideroblastic anaemia. Br 7 Haematol 1965;II:70-85.

3 Peto TEA, Pippard MJ, Weatherall DJ. Iron overload in mild sideroblastic anaemias. Lancet 1983; i:375-8.

4 Astrin KH, Bishop DF. Assignment of human erythroid delta aminolevulinate synthase (ALAS2) to the X chromosome. Cytogenet Cell Genet 1989;51:953-4A

5 Cox TC, Bawden MJ, Abraham NG, et al. Erythroid 5- aminolevulinate synthase is located on the $\mathrm{X}$ chromosome. Am ₹ Hum Genet 1990;46:107-11.

6 Cotter PD, Willard HF, Gorski JL, Bishop DF. Assignmen of the human erythroid $\delta$-aminolevulinate synthase (ALAS2) to a distal subregion of band Xp11.21 by PCR analysis of somatic cell hybrids containing $\mathrm{X}$;autosome translocations. Genomics 1992;13:211-12.

7 Conboy JG, Cox TC, Bottomley SS, et al. Human erythroid 5-aminolevulinate synthase. F Biol Chem 1992;266:18753 8.

8 Cotter PD, Bauman M, Bishop DF. Enzymatic defect in "X-linked" sideroblastic anaemia: molecular evidence fo erythroid 5-aminolevulinate synthase deficiency. Proc Nat Acad Sci USA 1992;89:4028-32.

9 Cox TC, Bottomley SS, Wiley JS, et al. X-linked pyridoxineresponsive sideroblastic anaemia due to a $\mathrm{THR}^{388}$-to-SER substitution in erythroid 5 -aminolevulinate synthase. $N$ Engl F Med 1994;330:675-9.

10 Pagon RA, Bird TD, Detter JC, Pierce I. Hereditary sideroblastic anaemia and ataxia: an X linked recessive disorder. Med Genet 1985;22:267-73.

11 Raskind WH, Wijsman E, Pagon RA, et al. X-linked sideroblastic anaemia and ataxia: linkage to phosphoglycerate kinase at Xq13. Am f Hum Genet 1991;48:335-41.

12 Cox TC, Kozman HM, Raskind WH, et al. Identification of a highly polymorphic marker in intron 7 of the ALAS2 of a highly polymorphic marker in intron 7 of the ALAS2 gene and the suggestion of at least two loci for X-linked
sideroblastic anaemia. Hum Mol Genet 1992;1:639-41.

13 Dewald GW, Pierre RV, Phyliky RL. Three patients with structurally abnormal X chromosomes, each with Xq13 structurally abnormal $\mathrm{X}$ chromosomes, each with $\mathrm{Xq13}$ breakpoints and a history of idiopath

14 Davies KE, Mandel JL, Monaco AP, et al. Report of the committee on the genetic constitution of the $\mathrm{X}$ chrocommittee on the genetic constitution of the

15 Beggs AH, Kunkel LM. A polymorphic CACA repeat in the $3^{\prime}$ untranslated region of dystrophin. Nucleic Acids Res 1990;18:1931

16 Roberts RG, Cole CG, Hart KA, et al. Rapid carrier and prenatal diagnosis of Duchenne and Becker muscular dystrophy. Nucleic Acids Res 1989;17:811.

17 Feener CA, Boyce FM, Kunkel LM. Rapid detection of CA polymorphisms in cloned DNA: application to the $5^{\prime}$ region of the dystrophin gene. Am $\mathfrak{f}$ Hum Genet 1991;48: regi-7.

18 Konradi C, Ozelius L, Breakfield XO. Highly polymorphic (GT) repeat sequence in intron 11 of the human MAOB gene. Genomics 1992;12:176-7.

19 Luty JA, Guo Z, Willard HF, et al. Five polymorphic microsatellite VNTRs on the human X chromosome. Am $\mathcal{f}$ Hum Genet 1990;46:776-83.

20 Browne DL, Zonana J, Litt M. Dinucleotide repeat polymorphism at the PGK1P1 locus. Nucleic Acids Res 1991; 20:1169.

21 Weber JL, Kwitek AE, May PE, et al. Dinucleotide repeat polymorphisms at the DXS453, DXS454 and DXS458 polymorphisms acids Res 1990;18:4037.

22 Lafreniere RG, Brown CJ, Powers VE, et al. Physical mapping of 60 DNA markers in the p21.1-q21.3 region of the ping of 60 DNA markers in the p21.1-q21.3 region

23 Graeber MB, Monaco AP, Chelly J, Muller U. Isolation of DNTR polymorphisms from yeast artificial chromosomes encompassing $\mathrm{X}$ chromoso

24 Winship PR, Rees DJG, Alkan M. Detection of polyinship PR, Rees DjG, Alkan M. Detine dinucleotides morphisms at cytosine phosphoguanadine dinucleotides and diagn.

25 Kogan SC, Doherty M, Gitschier J. An improved method for prenatal diagnosis of genetic diseases by analysis of amplified DNA sequences: application to haemophilia $A$ $N$ Engl f Med 1987;317:985-90.

26 Noble JS, Taylor GR, Stewart AD, et al. A rapid PCRbased method to distinguish between fetal and maternal cells in chorionic biopsies using microsatellite polymorphisms. Disease Markers 1991;9:301-6.

27 NIH/CEPH Collaborative Mapping Group. A comprehensive genetic linkage map of the human genome. Science 1992;258:67-83,148-62. 